\title{
Histidine Dissimilation in Streptomyces coelicolor
}

\author{
By K. E. KENDRICK† AND M. L. WHEELIS* \\ Department of Bacteriology, University of California, Davis, California 95616, U.S.A.
}

(Received 17 November 1981; revised 17 February 1982)

A growth technique that allows strains of Streptomyces coelicolor to grow dispersed in defined liquid medium has been devised and used to determine the pathway of histidine degradation by $S$. coelicolor. Enzymic, chromatographic and stoichiometric analyses indicated that histidine is dissimilated via $N$-formyl-L-glutamic acid. The enzymes for histidine utilization (hut) are induced when histidine or urocanate is included in the culture medium. Biochemical evidence suggested that urocanate, or a further metabolite, is the physiological inducer. Three hut mutants were isolated and characterized. Two of the mutants exhibit an uninducible phenotype, whereas the third mutant appears to be defective in the structural gene for formiminoglutamate iminohydrolase. Haploid recombinant analysis was employed to locate all three mutations in the left empty region of the chromosomal map.

\section{INTRODUCTION}

The pathways of histidine utilization have been elucidated for a limited number of bacteria, comprising three taxonomic groups (Fig. 1). The pathway in the enteric bacteria and in Bacillus subtilis (enteric-Bacillus pathway) includes as intermediates urocanate, IPA and FIG. Upon enzymic hydrolysis of FIG, formamide is excreted into the culture fluid (Kaminskas et al., 1970; Lund \& Magasanik, 1965; Neidhardt \& Magasanik, 1957), and glutamate serves as both carbon and energy source. In the pseudomonads, an amino group is cleaved from FIG to produce ammonia and $N$-formyl-L-glutamate (formylglutamate); the latter compound in turn is hydrolysed to formate and glutamate (Coote \& Hassall, 1973a; Rao \& Greenberg, 1961; Tabor \& Mehler, 1954; Lessie \& Neidhardt, 1967).

For comparative purposes, we chose to investigate histidine dissimilation in Streptomyces coelicolor. We selected this species because of the extensive knowledge and relative ease of analysis of its genetic system (Hopwood, 1967a; Hopwood et al., 1973). As a group, streptomycetes are of interest because of the novel conformation of their genetic maps, suggestive of a total genome duplication during the organism's evolution (Hopwood, 1967 b). Additionally, genetic analysis of a large number of markers in $S$. coelicolor reveals a map divisible into four quadrants (Hopwood et al., 1973). The upper and lower quadrants contain many loci, whereas only three markers, encoding presumed integration sites of an actinophage (Dowding \& Hopwood, 1973) and a sex factor (Hopwood et al., 1973), and a site involved in the production of extracellular agarase (Hodgson \& Chater, 1981) have been mapped in the right and left 'empty regions.'

In order to effectively combine genetic and biochemical analyses of streptomycetes, we have developed a technique by which cultures grow dispersed in defined liquid media. We have applied this technique to the determination of the pathway of histidine utilization in $S$. coelicolor, as well as to the characterization of some mutants defective in the dissimilation of histidine.

† Present address: Department of Biochemistry, University of Wisconsin, Madison, Wisconsin 53706, U.S.A.

Abbreviations: FIG, formiminoglutamic acid; IPA, imidazolonepropionic acid; PEG, polyethylene glycol 6000 . 
<smiles></smiles>

L-Histidine<smiles>Cc1ncc(C=CC(=O)O)[nH]1</smiles><smiles>O=C(O)CCC1NCNC1=O</smiles>

Imidazolonepropionic acid $\int_{\substack{\mathrm{H}_{2} \mathrm{O} \\ \text { imidazolonepropionate } \\ \text { hydrolase }}}$<smiles>N=CNC(C=O)C=CC(=O)O</smiles>

Formiminoglutamic

formiminoglutamate formiminohydrolase

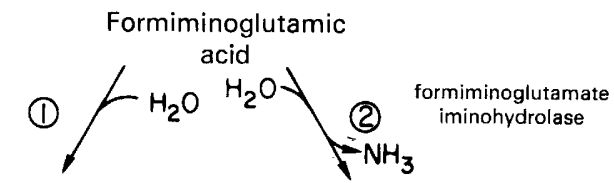<smiles>CC(C)=O</smiles>

Glutamic acid

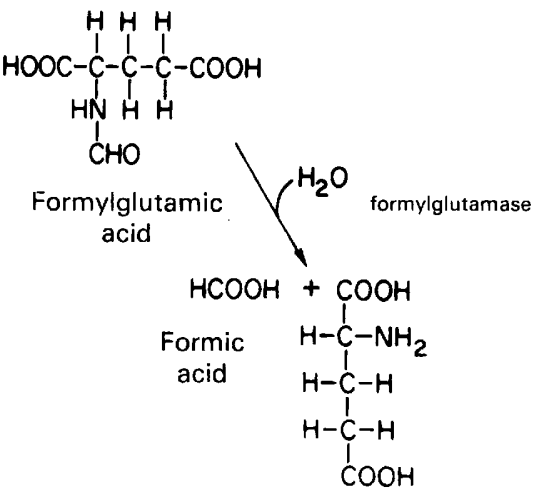

Glutamic acid

Fig. 1. The pathways of histidine dissimilation by bacteria. Pathway 1 is found in the enteric bacteria and Bacillus subtilis; pathway 2 is found in the pseudomonads and Streptomyces coelicolor. 
Table 1. Lists of strains of Streptomyces coelicolor

Strain

1147

1190/VP5

1258

1864

2239

$\mathrm{J} 650$

H-949

SMW9

SMW13

SMW30

SMW31

SMW32

SMW 33

SMW37

SMW 100

SKK 707

SKK 708

SKK 709

SKK 711

SKK 712
Genotype

Wild-type

hisA1 uraA1 strA1/VP5

proA1 hisA1 argA1 uraA1 cysD18 strAl

nicAl pheAl uraAl adeCV10 strA5 VP5def*

pabAl argA1 cysB6 strAl

mthB2 cysD18 agaA7

proAl cysA 15 argAl uraA1, nicAl tps-30

proAl cysA15 argAl uraA1, nicAl tps-30 acrC100

mthB2 cysD18 agaA 7 bka-1

hut 1

hut -2 mthB2 cysD18 agaA7 bka-1

hut -2 tps-30

hut-I uraAl pheAl strA5 VP5def

hut-7

Wild-type

pabAl argAl strAl uraAl

pabAl argAl strAl uraAl

hut-1 pabAl strAl

hut-I his $A 1$ strAI

hut-7 uraA1 pabA1 strAI
Fertility

Source

IF D. A. Hopwood

UF D. A. Hopwood

NF D. A. Hopwood

NF D. A. Hopwood

UF D. A. Hopwood

NF D. A. Hopwood

NF D. A. Hopwood

ND H-949; spontaneous acriflavine ${ }^{r}$

ND J650; MOP-NUV†

ND SMW 100; MOP-NUV

ND SMW 13; MOP-NUV

NF $\ddagger \quad$ SMW31 $\times$ SMW9

ND $\quad$ SMW30 × 1864

ND SMW100; FUV§

ND 1147 ; spontaneous

NF $2239 \times 1258$

NF $2239 \times 1258$

NF SKK $708 \times$ SMW30

NF $\quad$ SKK $709 \times 1258$

NF SKK $707 \times$ SMW37

ND, Not determined.

- VP5def confers resistance to infection by VP5; acrC100 describes a new allele conferring resistance to acriflavine; all other markers not described in the text are as presented in Hopwood et al. (1973).

† Mutagenesis with 8-methoxypsoralen and near-UV light.

$\ddagger$ The SMW- and SKK-prefixed strains were determined to be NF by virtue of their inability to produce an extracellular agarase (Hodgson \& Chater, 1981).

$\S$ Mutagenesis with far-UV light.

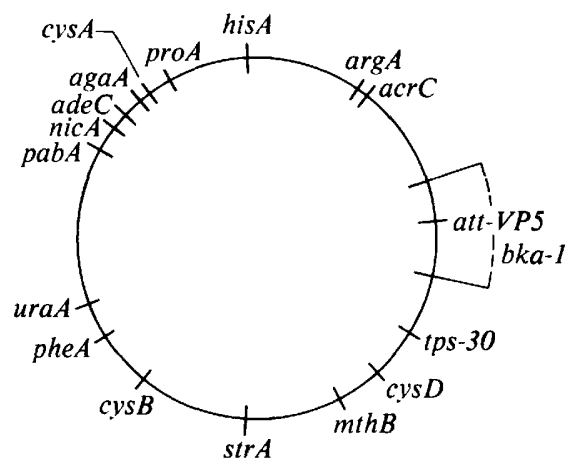

Fig. 2. Map positions of markers used in this study.

\section{METHODS}

Bacterial strains and phage techniques. The strains used in this study are listed in Table 1 and the map positions of the markers are shown in Fig. 2. All are derivatives of $S$. coelicolor A3(2). In the course of this investigation, strain 1147 (wild-type) appeared to become ultrafertile, presumably due to loss of the sex factor SCP1, which has been reported to occur at a spontaneous frequency of $10^{-2}$ (Vivian \& Hopwood, 1970). We have designated this new 'wild-type' strain SMW100.

The phage techniques of Dowding (1973) and Dowding \& Hopwood (1973) were used to isolate a spontaneous clear plaque mutant of actinophage VP5 from a lysogenized strain, 1190/VP5.

Media. For culture maintenance, we devised a sporulation medium (SpM) containing (w/v): $0.1 \%$ Bacto-peptone; $0.5 \%$ yeast extract; $0.5 \% \mathrm{NaCl} ; 0.5 \%$ glucose; $1.5 \%$ agar. This medium allowed abundant sporulation within 4 to $8 \mathrm{~d}$ of incubation at $34^{\circ} \mathrm{C}$. Stock cultures were stored on SpM slants at $4{ }^{\circ} \mathrm{C}$.

The minimal medium of Hopwood (1967a) provided the basis for the solid minimal medium used in this investigation: $0.005 \%(\mathrm{w} / \mathrm{v})$ ferric ammonium citrate; $0.01 \%(\mathrm{w} / \mathrm{v}) \mathrm{MgSO}_{4} .7 \mathrm{H}_{2} \mathrm{O} ; 3 \mathrm{~mm}$-sodium-potassium 
phosphate buffer, pH $6.8 ; 1.5 \%(\mathrm{w} / \mathrm{v})$ Oxoid purified agar. Usually asparagine at $0.025 \%(\mathrm{w} / \mathrm{v})$ served as the nitrogen source, with $10 \mathrm{~mm}$-glucose as the carbon source. Occasionally, however, $0.025 \%(\mathrm{w} / \mathrm{v})\left(\mathrm{NH}_{4}\right)_{2} \mathrm{SO}_{4}$ was substituted for $\mathrm{L}$-asparagine. When histidine was the carbon and nitrogen source, those growth factors that could themselves function as sources of carbon or nitrogen were added at one-tenth of the concentration recommended by Hopwood $(1967 a)$. This adjustment was necessary to prevent growth at the expense of the supplements, particularly when histidine utilization mutants were being sought.

The liquid minimal medium used was that of Palleroni \& Doudoroff (1972): $0.005 \%(\mathrm{w} / \mathrm{v})$ ferric ammonium citrate; $33 \mathrm{~mm}$-sodium-potassium phosphate buffer, $\mathrm{pH} 6.8 ; 0.05 \%(\mathrm{w} / \mathrm{v}) \mathrm{MgSO}_{4} .7 \mathrm{H}_{2} \mathrm{O} ; 0.0005 \%(\mathrm{w} / \mathrm{v})$ $\mathrm{CaCl}_{2}, 2 \mathrm{H}_{2} \mathrm{O}$. The latter two components were mixed at 100 -fold concentration, autoclaved, and added to the first two components to prepare the base solution ( $\mathrm{P} / \mathrm{D}$ base). Carbon and nitrogen compounds were added after separate sterilization. The concentrations of these nutrients varied depending on the experiment, and are specified in Results.

The complex liquid medium was L-broth (Lennox, 1955). For all liquid cultures, $5 \%(\mathrm{w} / \mathrm{v})$ PEG was included in the medium, and a coiled spring was inserted securely around the inside bottom periphery of the flask. Springs were made of $1 \mathrm{~mm}$ stainless steel or nichrome wire, were $1 \mathrm{~cm}$ in width, and had five turns of the helix per inch. Because the PEG appeared to inhibit spore germination, it was added after germination had occurred (usually 6 to $10 \mathrm{~h}$ post-inoculation, depending on the medium).

Growth of cultures. Aqueous spore suspensions served as inoculum for liquid cultures. Spores were harvested from confluently sporulated cultures on SpM plates, by the glass bead technique of Hirsch \& Ensign (1975). Spores were removed from the beads with sterile distilled water, washed once by centrifugation, and stored in water at $4^{\circ} \mathrm{C}$.

All liquid cultures were incubated at $34^{\circ} \mathrm{C}$. The culture volume was 0.2 to 0.25 times the flask volume, and the flasks were shaken at $250 \mathrm{rev} \cdot \mathrm{min}^{-1}$ on a gyrotory shaker. Growth was measured with a Klett-Summerson photocolorimeter equipped with blue filter number 42 .

Either spores or mycelia were used as inoculum for plate cultures. The temperature of incubation of plate cultures was $34^{\circ} \mathrm{C}$ except for the scoring of heat-sensitive strains, for which the restrictive temperature was $39.5^{\circ} \mathrm{C}$.

Mutagenesis and mutant analysis. In some cases we followed the mutagenesis procedure of Townsend et al. (1971), employing 8-methoxypsoralen and irradiation with near-UV light. Alternatively, we irradiated spore suspensions with far-UV light. In either instance spore suspensions were irradiated to a survival of $1 \%$.

We detected hut mutants in two ways. In the first method irradiated spores were plated on glucose/asparagine minimal medium. After sporulation, colonies were replicated to a plate containing histidine as sole source of carbon and nitrogen, and to a control plate containing glucose and ammonia. Strains SMW30 and SMW31 were isolated in this way. In the second method, mutagenized spores were plated on to minimal medium containing 10 mM-histidine and $1 \mathrm{mM}$-glutamate. Small colonies were transferred to a glucose/asparagine minimal plate and were replicated as described above. Strain SMW37 was isolated by this method.

The haploid recombinant analytical technique of Hopwood (1967a) served to map mutations and to transfer hut mutations into prototrophic backgrounds.

For enzyme analysis, the hut mutants were grown in P/D base containing glucose, glutamate and histidine, each at $10 \mathrm{~mm}$. Further analyses made use of other combinations of carbon and nitrogen compounds, as specified in Results.

Preparation of cell-free extracts. All steps were carried out at $4^{\circ} \mathrm{C}$. Cultures were harvested in the exponential phase $\left(150-200 \mathrm{Klett}_{42}\right.$ units) by centrifugation at $27000 \mathrm{~g}$. The pellet was washed twice with $1 \mathrm{M}-\mathrm{KCl}$ to remove extracellular proteases (Nakayama et al., 1977). The mycelia were suspended in 0.02 times the culture volume of $50 \mathrm{~mm}$-imidazole $/ \mathrm{HCl}$, pH 7.2, containing $1 \mathrm{~mm}$-phenylmethylsulphonyl fluoride. An Aminco French Pressure Cell operating at $110 \mathrm{MPa}$ was used to break the mycelia. Cell debris was removed by centrifugation at $35000 \mathrm{~g}$ for $20 \mathrm{~min}$. The supernatant was used as the crude extract for enzyme analyses.

Chemical determinations. Protein was measured by the method of Ehresmann et al. (1973), using bovine serum albumin (Armour Pharmaceutical Co.) as the standard. The alkali-labile ammonia technique of Lund \& Magasanik (1965) was used to measure formamide. Ammonia was determined as indicated below for the FIG iminohydrolase assay.

Enzyme assays. Absorbance measurements were made with a Beckman Acta III spectrophotometer. Enzymic reactions were maintained at $25^{\circ} \mathrm{C}$. One unit of activity is defined as the net conversion of $1 \mu$ mol of substrate per minute. Specific activity is defined as milliunits (mU) per mg protein.

Histidine ammonia-lyase (histidase; EC 4.3.1.3). The optimal reaction mixture contained: $1.1 \mathrm{ml}$ of $50 \mathrm{~mm}$-Tris/HCl, pH $8 \cdot 5 ; 5-20 \mu$ l extract; $0.05 \mathrm{ml}$ of $100 \mathrm{~mm}$-L-histidine to start the reaction. Absorbance was measured at $277 \mathrm{~nm}$, at which wavelength the absorption coefficient for the product, urocanic acid, is $18.8 \times 10^{3} \mathrm{l}$ $\mathrm{mol}^{-1} \mathrm{~cm}^{-1}$ (Rechler, 1969). At this reaction $\mathrm{pH}$, the activity of urocanase is negligible.

Urocanate hydratase (urocanase; EC 4.2.1.49). Extract $(5-20 \mu \mathrm{l})$ was combined with $1.1 \mathrm{ml} 50 \mathrm{~mm}$ potassium phosphate buffer, $\mathrm{pH} 7 \cdot 2$, and $10 \mu \mathrm{l}$ of $10 \mathrm{mM}$-urocanate, $\mathrm{pH} 7 \cdot 0$, was added to initiate the reaction. 
The decrease in absorbance was monitored at $300 \mathrm{~nm}$, at which wavelength urocanate has an absorption coefficient of $7.05 \times 10^{3} 1 \mathrm{~mol}^{-1} \mathrm{~cm}^{-1}$. This wavelength was used in order to avoid interference by IPA, as well as to decrease spectrophotometric noise that occurs as a consequence of the high absorbance of urocanate at $277 \mathrm{~nm}$.

Imidazolonepropionase (EC 3.5.2.7). The method for in situ generation of imidazolonepropionate was used (Rao \& Greenberg, 1961). $1.1 \mathrm{ml}$ of $50 \mathrm{~mm}$-potassium phosphate, pH 7.2, was mixed with $20 \mu \mathrm{l}$ of 10 mM-urocanate, pH 7.0. Sufficient partially purified urocanase from Pseudomonas putida PMW99 (Leidigh \& Wheelis, $1973 b$ ) was added to effect complete conversion of the substrate in approximately $10 \mathrm{~min}$. This conversion was verified by monitoring the absorbance change at $300 \mathrm{~nm}$. When the rate of change reached zero, $10-20 \mu \mathrm{l}$ of streptomycete extract was added, and the absorbance was monitored at $263 \mathrm{~nm}$, where IPA absorbs maximally with an absorption coefficient of $4 \times 10^{3} 1 \mathrm{~mol}^{-1} \mathrm{~cm}^{-1}$ (Rao \& Greenberg, 1961). It was necessary to run simultaneously a control reaction without extract, because IPA spontaneously decomposes at neutral pH.

Formiminoglutamate iminohydrolase. Ammonia generation was measured by a modified Berthelot reaction (Ecker \& Lockhart, 1961; Gordon et al., 1978). Extract was diluted with an equal volume of 50 mM-imidazole/ $\mathrm{HCl}, \mathrm{pH} 7.2 ; 2 \mathrm{mM}$-FIG (Sigma) was added to initiate the reaction. At intervals $0.2 \mathrm{ml}$ samples were withdrawn into $0.3 \mathrm{ml}$ of distilled water and $2.5 \mathrm{ml}$ of Reagent $\mathrm{A}(0.47 \mathrm{~g}$ sodium citrate, dihydrate; $0.17 \mathrm{~g}$ citric acid; $0.96 \mathrm{~g}$ phenol; $48 \mathrm{ml}$ water). After vortexing, $1.0 \mathrm{ml}$ of Reagent $\mathrm{B}\left[0.6 \mathrm{~g} \mathrm{H}_{3} \mathrm{BO}_{3} ; 0.8 \mathrm{~g} \mathrm{NaOH} ; 3.0 \mathrm{ml}\right.$ of $5.25 \%$ sodium hypochlorite (commercial bleach); $17 \mathrm{ml}$ water] was added. The solution was mixed thoroughly. Each assay tube was capped and heated at $100^{\circ} \mathrm{C}$ for $5 \mathrm{~min}$, and was then rapidly chilled on ice. The absorbance at $615 \mathrm{~nm}$ was compared with a standard curve prepared with $\mathrm{NH}_{4} \mathrm{Cl}$ solutions.

$N$-Formylglutamate hydrolase (formylglutamase). A coupled enzyme assay was developed to measure the rate of generation of glutamate from the substrate, formylglutamate. Bovine liver glutamate dehydrogenase served as the coupling enzyme; $1.1 \mathrm{ml}$ of $100 \mathrm{mM}$-Tris/ $\mathrm{HCl}, \mathrm{pH} 8.5$, was combined with $1 \mu \mathrm{l}$ (containing 1.5 units) of glutamate dehydrogenase (Calbiochem) that had been dialysed against $50 \mathrm{~mm}$-potassium phosphate, $\mathrm{pH} 7.2$, to remove $\left(\mathrm{NH}_{4}\right)_{2} \mathrm{SO}_{4}$. This amount of glutamate dehydrogenase was not rate-limiting. Ten $\mu \mathrm{l}$ of $250 \mathrm{mM}-\beta$-NAD (Sigma) and $10 \mu \mathrm{l}$ of $100 \mathrm{~mm}$-formylglutamic acid were added, followed by 10-20 $\mu$ l of extract. Absorbance was measured at $340 \mathrm{~nm}$; the absorption coefficient of NADH at this wavelength is $6.22 \times 10^{3} 1 \mathrm{~mol}^{-1} \mathrm{~cm}^{-1}$ (Segel, 1968). Assays without substrate or extract were run in parallel, to control for both contaminating glutamic acid in the synthetic formylglutamic acid and the high concentration of glutamate in a typical extract. When formyltransferase activity was assayed (Silverman, 1962), 0.1 mM-tetrahydrofolate was included in the reaction mixture.

Paper chromatography. A crude extract was prepared from an exponential culture of strain SMW100 grown in glucose/histidine minimal medium. After supplying the extract with 2 mM-urocanate and incubating at $25^{\circ} \mathrm{C}$, samples were withdrawn, acidified and analysed by ascending paper chromatography using as solvent butan-2-ol/formic acid/water (19:2:6 by vol.; Hassall, 1971). Formylglutamic acid was detected by its reaction with Brom-cresol Purple.

Chemicals. The sources of special chemicals are noted in the text. All other chemicals were of the highest purity commercially available. $N$-Formylglutamic acid was synthesized by the method of Tabor \& Mehler (1954). Melting point determination and paper chromatography served to identify the synthetic compound as $N$-formylglutamic acid.

\section{RESULTS}

\section{Growth in liquid culture}

Previous techniques for growth of $S$. coelicolor in liquid culture employed $34 \%(\mathrm{w} / \mathrm{v})$ sucrose and $1 \%(\mathrm{w} / \mathrm{v}) \mathrm{MgCl}_{2}$ (Hopwood et al., 1973), to reduce mycelial aggregation which leads to inaccurate measurements of growth. To circumvent the possibility of physiological damage from excessive osmolarity or ionic strength, we substituted PEG in the medium. At the optimal concentration of $5 \%$, and in concert with the coiled spring, the PEG allowed sufficient microcolony dispersion for reproducible turbidometric measurement of growth. By this culture method it was determined that histidine was a more favourable nitrogen source than glutamate or ammonia (growth rate constants, with glucose, of $0.24 \mathrm{~h}^{-1}, 0.19 \mathrm{~h}^{-1}$ and $0.20 \mathrm{~h}^{-1}$, respectively).

\section{Determination of the pathway}

The enteric-Bacillus pathway of histidine catabolism is characterized by the excretion of formamide, which is not further metabolized (Neidhardt \& Magasanik, 1957). However, formamide apparently is not an end-product of histidine dissimilation in $S$. coelicolor, since 


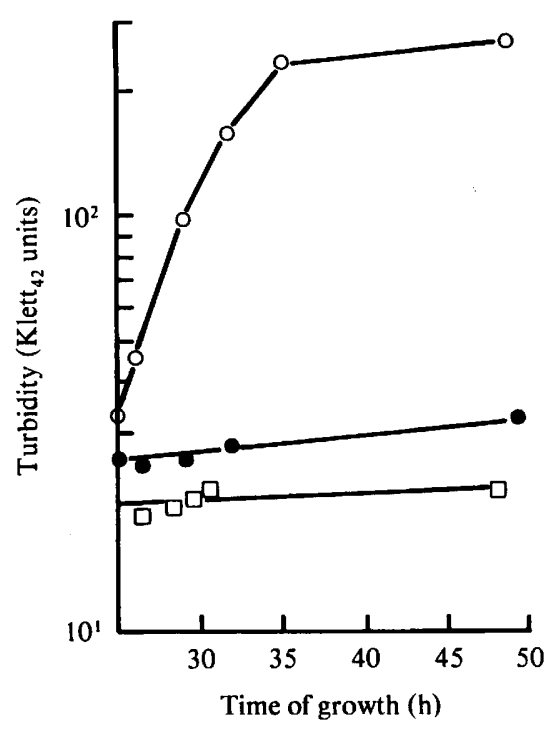

Fig. 3

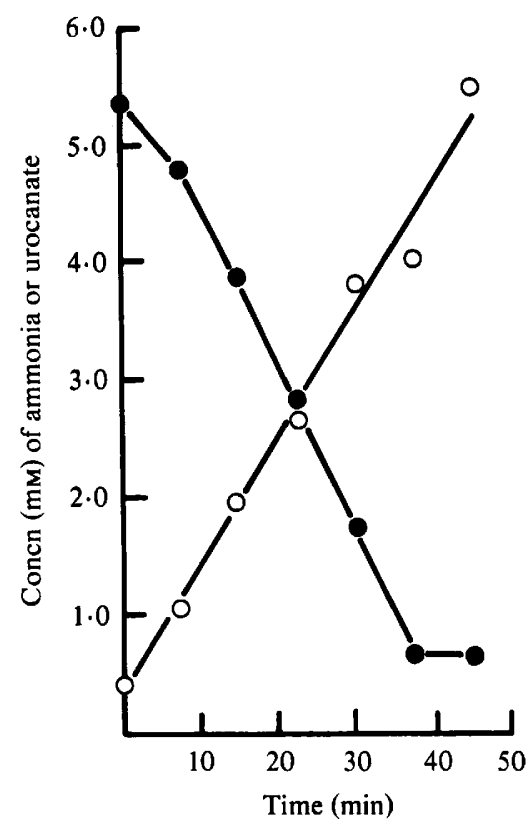

Fig. 4

Fig. 3. Growth of the wild-type strain, SMW100, on glucose and $10 \mathrm{mM}$-L-histidine (O) or 2 mM-urocanate $(O)$ or 1 mM-formamide ( $\square$ ).

Fig. 4. Stoichiometry between urocanate degraded $(O)$ and ammonia produced $(O)$ by a crude extract of strain SMW100 grown on $10 \mathrm{mM}$-L-histidine. Urocanate was measured by its absorbance at $277 \mathrm{~nm}$, ammonia by the modified Berthelot reaction.

analysis of the culture supernatant of cells growing on glucose plus histidine showed no formamide. That formamide is not an intermediate either is indicated by the fact that formamide did not serve as sole nitrogen source in conjunction with glucose (Fig. 3), nor was it degraded by a crude extract of mycelia grown on glucose and histidine.

Paper chromatography indicated the time-dependent production of formylglutamate from urocanate by an extract of cells grown on glucose and histidine. The same extract produced stoichiometric quantities of ammonia from urocanate (Fig. 4). This stoichiometry is consistent with the pseudomonad pathway of histidine utilization, but not with the enteric-Bacillus pathway unless formamide were enzymically hydrolysed. Ammonia was not evolved, however, when the extract from glucose/histidine grown cells was provided with formamide as substrate.

Enzyme assays were carried out to corroborate the chemical evidence for participation of formylglutamate as intermediate. The first four enzymes of the pathway were all present in significant amounts in induced cultures (Table 2). Formylglutamase, the fifth enzyme functional in the dissimilation of histidine by pseudomonads, was not detected in extracts prepared from $S$. coelicolor. Neither formylglutamate hydrolase activity nor formyltransferase activity, which occurs in hog liver (Silverman, 1962), was detectable. $N$ Acetylglutamate could not serve as substrate for the coupled assay, suggesting that in vivo conversion of histidine to glutamate did not rely on an acetylglutamase having low but metabolically significant affinity for formylglutamate. Growth of the culture in succinate/ histidine minimal medium also failed to give rise to any detectable formylglutamase activity. Whole cells of glucose/histidine grown $S$. coelicolor, when assayed with an oxygen electrode, did not take up oxygen when given histidine as substrate; this observation suggested that complete oxidation of histidine does not occur in mycelia growing on glucose plus histidine. 
Table 2. Specific activities of the histidine-degrading enzymes in the wild-type strain, SMW100

Glucose, ammonia and glutamate were each provided at $10 \mathrm{~mm}$. All other compounds were supplied at the concentrations noted. Activities are presented as $\mathrm{mU}(\mathrm{mg} \text { protein })^{-1}$. Values in parentheses indicate the standard deviation and number of determinations, respectively.

Growth condition

Glucose + ammonia + glutamate

Glucose + glutamate

Glucose +10 mM-histidine

Glucose + ammonia + 10 mM-histidine

Glucose + glutamate +1 mM-histidine

Glucose + glutamate + 5 mm-histidine

Glucose + glutamate + 10 mM-histidine

Glutamate +10 mm-histidine

L-Broth + glucose +10 mM-histidine

Glucose + glutamate +2 mM-urocanate

Glucose + glutamate +5 mM-dihydrourocanate

Glucose + glutamate + $10 \mathrm{~mm}$-formylglutamate

$10 \mathrm{~mm}$-Succinate $+10 \mathrm{~mm}$-histidine

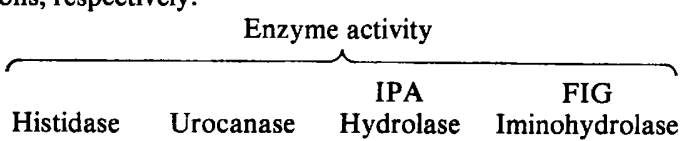

$\begin{array}{cccc}0.6 & 0.7 & <5 & <5 \\ 0.3 & <0.1 & <5 & <5 \\ 31.0 & 18.0 & 46 & 14 \\ 30.0 & 9.0 & 43 & 39 \\ ( \pm 13.2 ; 2) & ( \pm 2.4 ; 2) & ( \pm 18 ; 2) & ( \pm 1 ; 2) \\ 35.0 & 7.0 & 15 & 45 \\ 45.0 & 10.0 & 34 & 46 \\ ( \pm 10.4 ; 5) & ( \pm 3 \cdot 7 ; 5) & ( \pm 10 ; 5) & ( \pm 17 ; 5) \\ 35.0 & 14 \cdot 0 & 35 & 23 \\ ( \pm 10.5 ; 4) & ( \pm 1.7 ; 4) & ( \pm 15 ; 3) & ( \pm 0 ; 2) \\ 39.0 & 18.0 & 62 & 31 \\ 34.0 & 9.0 & 35 & 25 \\ 5.0 & 1.0 & <5 & <5 \\ ( \pm 1.1 ; 4) & ( \pm 0.5 ; 4) & ( \pm 0 ; 4) & ( \pm 0 ; 4) \\ 0.1 & 0.1 & <5 & <5 \\ <0.1 & 0.1 & <5 & <5 \\ 46.0 & 19.0 & \text { ND } & \text { ND }\end{array}$

ND, Not determined.

\section{Enzyme induction}

The specific activities of the hut enzymes from the wild-type strain grown under a variety of conditions are presented in Table 2. The first four enzymes of the pathway are inducible, either in the presence of histidine or to a lesser extent when urocanate is included in the medium. Inclusion of formylglutamate in the growth medium does not result in induction. The level of induction depends solely on the inclusion of histidine or urocanate; the additional presence of ammonia, glutamate or complex nitrogen sources does not alter the activities of the hut enzymes. There is, likewise, no specific glucose effect: replacement of glucose by glutamate in the growth medium does not enhance activities of the enzymes of histidine catabolism.

The results reported in Table 2 are consistent with the role of either histidine or urocanate as inducer of the hut system. Other evidence suggests that urocanate, or a further metabolite, is the actual inducer: urocanate supplied at $2 \mathrm{~mm}$ cannot satisfy a histidine auxotrophic requirement for strain 1258 , whereas this same concentration of urocanate does result in low level induction of the hut system in strain SMW 100 (Table 2); thus the activity of urocanate as inducer is unlikely to be due to its conversion to histidine. The relatively poor induction achieved in the presence of urocanate is probably the result of poor transport. Consistent with this idea, we observed that urocanate is incapable of serving as sole source of nitrogen with glucose as carbon source (Fig. 3), and that the growth rate of the wild-type strain, supplied with histidine as sole nitrogen source, does not become maximal until the histidine concentration exceeds $5 \mathrm{mM}$. Further support for the hypothesis that transport of histidine or urocanate, like that of other catabolites, is the growth rate-determining step was provided by the high values $\left(\geq 1 \mathrm{mM}\right.$ ) of the apparent $K_{\mathrm{m}}$ constants for carbohydrate transport by $S$. coelicolor A3(2) (D. A. Hodgson, personal communication) and by $S$. violaceoruber (Sabater \& Asensio, 1973).

\section{Mutant analysis}

We isolated three strains defective in the utilization of histidine as sole source of carbon 


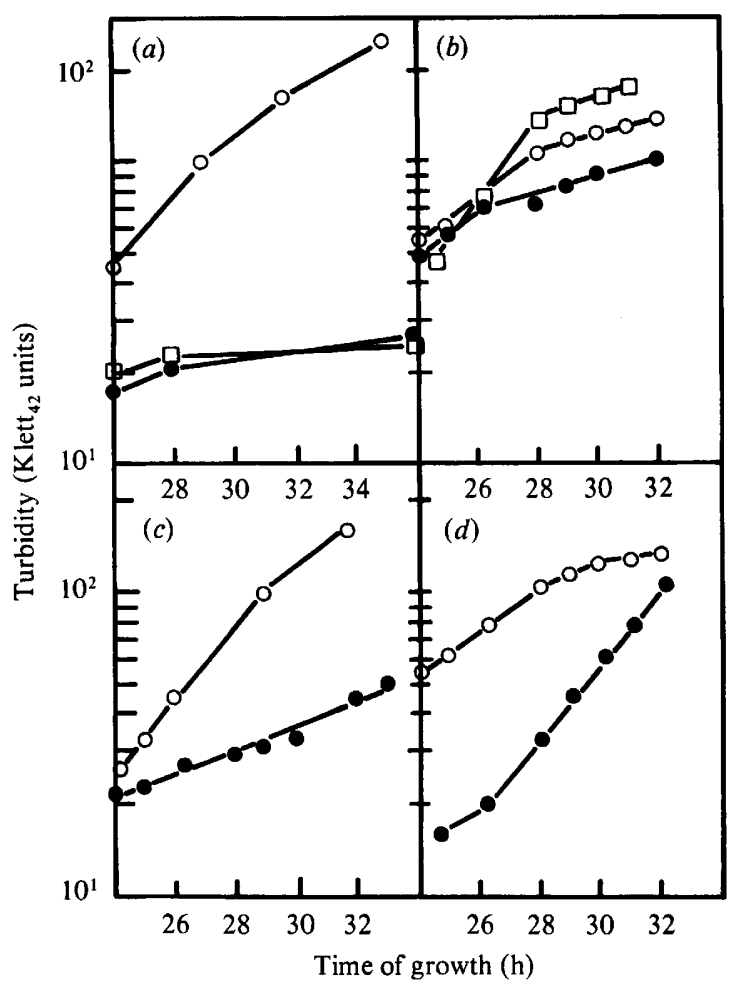

Fig. 5. Growth of the mutant strains in minimal medium. (a) $10 \mathrm{~mm}$-glucose, $10 \mathrm{~mm}$-histidine: SMW100 (O); SMW37 (O); SMW30 (a). (b) $10 \mathrm{mM}$-Glucose, $10 \mathrm{mM}$ - $\left(\mathrm{NH}_{4}\right)_{2} \mathrm{SO}_{4}$; symbols as in $(a)$. (c) $10 \mathrm{mM}$-Glucose, $10 \mathrm{~mm}$-histidine: SMW100 (O); SMW32 (O). (d) $10 \mathrm{mM}$-Glucose, $10 \mathrm{mM}$ $\left(\mathrm{NH}_{4}\right)_{2} \mathrm{SO}_{4}$ : symbols as in $(c)$.

and nitrogen. For all of the mutations, the frequency of spontaneous reversion is less than $4 \times$ $10^{-8}$. Mutations hut-1 and hut-7 confer the inability to utilize histidine (Fig. 5) or histidyl-histidine (data not shown) as the nitrogen source in liquid medium. Enzyme analysis of crude extracts prepared from SMW30 (hut-1) and SMW37 (hut-7) indicated that none of the first four enzymes was induced under any of the growth conditions used (Table 3). Growth of either strain on proline, arginine, phenylalanine or glutamate was unimpaired.

Analysis of the hut-2 mutation was complicated by the fact that it was originally obtained in an auxotroph, SMW31. Growth of strain SMW31 in liquid minimal medium was severely compromised, presumably because of inefficient transport of the growth factors. Therefore, strain SMW31 was crossed with strain SMW9 and a recombinant carrying hut-2 in a prototrophic background was isolated. This new strain, SMW32, grew quite well in glucose/ammonia minimal medium, and grew slowly at the expense of glucose plus histidine (Fig. 5). Enzyme induction studies suggested that hut-2 is a mutant allele of the structural gene for formiminoglutamate iminohydrolase (Table 3).

These three mutations were mapped by means of the haploid recombinant analysis described by Hopwood $(1967 a)$. In all cases selective crosses were made. The map position of hut-2 was established from the analysis diagrammed in Fig. 6. In the cross of strain SMW31 with strain 1258 , the two selected markers were his $A^{+}$and $\operatorname{str} A$. The presence of a second marker encoding a catabolic function, $b k a-1$, was exploited to determine the location of hut-2. The marker $b k a-1$, conferring the inability to use $p$-hydroxybenzoate as sole source of carbon, had been mapped previously in the right quadrant of the chromosomal map, between $\arg A$ and tps-30 (unpublished data; Fig. 2); the cross illustrated in Fig. $6(a)$ confirmed this position. The recombinant frequency of hut-2 suggested that this marker is 
Table 3. Specific activities of the histidine-degrading enzymes in the hut mutants

Glucose, glutamate and histidine were provided at $10 \mathrm{~mm}$; urocanate was provided at $5 \mathrm{~mm}$. Activities are expressed as $\mathrm{mU}$ ( $\mathrm{mg}$ protein $)^{-1}$. Values in parentheses indicate the standard deviation and number of determinations, respectively.

Strain Growth condition

$\begin{array}{ll}\text { SMW30 (hut-1) } & \text { Glucose + glutamate + histidine } \\ & \text { Glucose + glutamate + urocanate } \\ & \text { Glutamate + histidine } \\ \text { SMW32 (hut-2) } & \begin{array}{l}\text { Glucose + glutamate + histidine } \\ \text { SMW37 (hut }-7)\end{array} \\ & \begin{array}{l}\text { Glucose + glutamate + histidine } \\ \text { Glucose + glutamate + urocanate } \\ \text { Glutamate + histidine }\end{array}\end{array}$

$\begin{array}{cccc}\text { Erocanase } & \begin{array}{c}\text { IPA } \\ \text { Hydrolase }\end{array} & \begin{array}{c}\text { FIG } \\ \text { Iminohydrolase }\end{array} \\ 0.4 & 0.5 & <5 & <5 \\ ( \pm 0.3 ; 2) & ( \pm 0.3 ; 2) & & \\ 0.3 & 0.2 & <5 & <5 \\ ( \pm 0.1 ; 3) & ( \pm 0.1 ; 3) & ( \pm 0 ; 3) & ( \pm 0 ; 3) \\ 0.2 & 0.6 & <5 & <5 \\ 24.0 & 5.0 & 18 & <5 \\ ( \pm 1.2 ; 3) & ( \pm 1.5 ; 3) & ( \pm 8 ; 3) & ( \pm 0 ; 2) \\ 0.4 & 0.2 & <5 & <5 \\ <0.1 & <0.1 & \text { ND } & \text { ND } \\ <0.1 & 0.8 & <5 & <5\end{array}$

ND, Not determined.
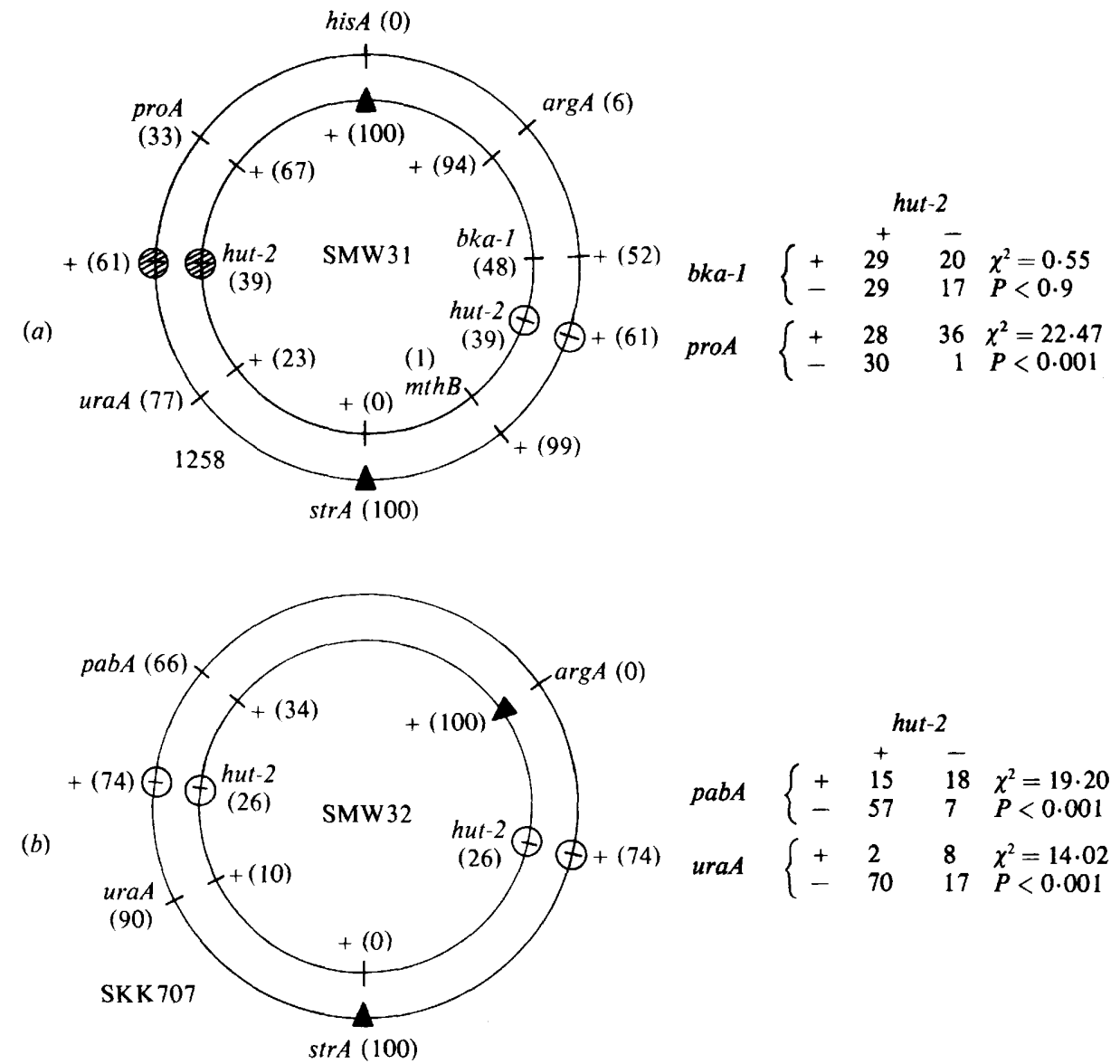

Fig. 6. (a) Cross SMW31 $\times 1258$. Strain SMW31 is depicted by the inner map, strain 1258 by the outer map. Selected markers are denoted by closed triangles $(\boldsymbol{A})$. Percentage inheritance of each allele is indicated in parentheses. The possible positions of the hut marker, based on gradient analysis, are indicated by circles. The numbers of recombinants of relevant genotypes are tabulated and analysed by the adjusted $\chi^{2}$ test, to give the probable location of the hut-2 marker (hatched circle). (b) Cross SMW32 $\times$ SKK 707. The data are presented as in part $(a)$. 
located in either the right or left quadrant. Adjusted $\chi^{2}$ analysis of the co-inheritance of non-selected markers indicated the independence of hut-2 and $b k a-1$ and the dependence of hut-2 and proA. A second cross, employing strain SMW32 and strain SKK707, located hut-2 between $p a b A$ and $u r a A$ or between strA and $\arg A$ (Fig. $6 b$ ). Taken together, these results unambiguously locate hut-2 within the previously designated left 'empty region.'

Further evidence suggested that hut-7 and hut-1 also map in the left quadrant. Analysis of allele ratios and multiple crossover events for the cross SMW37 $\times 1258$ localized hut-7 between proA and $u r a A$, and the cross of SMW33 $\times 1258$ indicated that hut-1 maps between proA and pheA (data not shown). The three hut mutations were crossed in pair-wise combinations to attempt to recover Hut $^{+}$recombinants. Whereas SMW31 $\times$SKK 712 (hut-2 $\times$ hut-7) gave rise to selectable $\mathrm{Hut}^{+}$recombinants, neither SMW31 $\times$SKK711 (hut-2 $\times$ hut-1) nor SKK $711 \times$ SKK 712 (hut-1 $\times$ hut-7) yielded Hut ${ }^{+}$recombinants upon selection for histidine utilization. Although we have been unable, for technical reasons, to map hut-1 or $h u t-7$ with respect to $p a b A$, the above results indicate that all three markers are closely linked. Either the mutation hut-1 lies between hut-2 and hut-7, or hut-1 may be a deletion that overlaps hut-2 and hut-7.

\section{DISCUSSION}

Measurements of growth rates of the wild-type strain of $S$. coelicolor showed that histidine is an excellent nitrogen source; no other single nitrogenous compound tested supports more rapid growth. The fact that histidine is preferred to ammonia, coupled with the observation that maximal induction of the histidine degradative enzymes occurs whenever histidine is present in the medium whether or not ammonia is present, indicates that the hut system of $S$. coelicolor is not strongly repressed by ammonia. That a weak nitrogen repression, effected by endogenously generated ammonia, does not occur is suggested by the observation that cultures grown in the presence of growth rate-limiting amounts of histidine are not super-induced for the hut enzymes.

The results suggest that histidine is dissimilated through a pathway identical to that found in some Pseudomonas species, in which formylglutamate is an intermediate. By this route, 2 mol ammonia are liberated per mol of histidine dissimilated. This stoichiometry contrasts with that of the enteric-Bacillus pathway, in which 1 mol of histidine leads to the release of a single mol of free ammonia.

Strain SMW32, which was shown by enzyme analysis to be defective in iminohydrolase production, grows more slowly than the wild-type on glucose/histidine medium, presumably because only one of the reactions that releases ammonia is still functional. An alternative explanation for the lower growth rate of strain SMW32 on glucose/histidine minimal medium is that FIG is somewhat toxic. However, since strain SMW32 grows at the wild-type rate in glucose/glutamate/histidine minimal medium (data not shown), this alternative suggestion appears unlikely.

Although no enzyme capable of formylglutamate hydrolysis was found in significant amounts in crude extracts, it is unlikely that the genetic information to encode such an enzyme is absent from this strain, since the wild-type strain grows well on a solid medium containing histidine as sole organic compound. Possibly formylglutamate hydrolysis occurs only when histidine serves as sole source of both carbon and nitrogen. If this were true, then the inability to detect formylglutamase in crude extracts would reflect the fact that the enzyme was not induced under the growth conditions used. (We have been unable to obtain reliable growth of $S$. coelicolor in liquid media with histidine as sole source of carbon and nitrogen.) This non-inducibility in turn would imply that the structural gene for hydrolysis of formylglutamate is regulated independently of those encoding the four remaining hut enzymes.

The results of the induction studies are consistent with histidine, urocanate, IPA or FIG 
acting as inducer. Dihydrourocanate, a gratuitous inducer in pseudomonads, does not induce the hut system of $S$. coelicolor. Circumstantial evidence suggests that, as in the enteric bacteria (Meiss et al., 1969; Schlesinger et al., 1965) and the pseudomonads (Coote \& Hassall, $1973 b$; Leidigh \& Wheelis, $1973 b$; Newell \& Lessie, 1970), urocanate (or possibly IPA or FIG) is an inducer of the hut system in S. coelicolor. If histidine were the sole inducer, the limited induction in the presence of urocanate would be due to a low degree of reversibility of the histidase reaction. However, since urocanate, at a concentration sufficient to induce the hut enzymes, cannot supply a histidine auxotroph with its requirement, it seems more likely that histidine is not the only physiological inducer. The low level of induction by urocanate is thus probably caused by the limited ability of the organism to transport urocanate.

Three mutants defective in utilization of histidine have been isolated. The mutation hut-2 most probably lies within the structural gene for FIG iminohydrolase. The nature(s) of the mutations hut-1 and hut-7, both of which result in non-inducibility of the hut enzymes, is unknown. Strains carrying either of these mutations retain basal activities of histidase and urocanase, suggesting that the inability of these strains to induce the enzymes for histidine dissimilation is due either to defects in their ability to transport histidine and urocanate (presumably via the same carrier protein), or to mutations in genes with regulatory functions. Because the hut enzymes are induced to comparable levels in the presence or absence of glucose, and since these mutant strains utilize as sole carbon and nitrogen source a variety of amino acids other than histidine, any regulatory defect would presumably be histidinespecific.

Four markers encoding dissimilatory functions have been located within the 'empty regions' of the genetic map of $S$. coelicolor. Mutations have been mapped in both the right quadrant (bka-1) and the left quadrant (hut-1, hut-2, hut-7). The location of bka and hut genes in the heretofore designated 'empty' regions of the map leads to our speculation that the corresponding regions of the $S$. coelicolor genome may be specialized to encode enzymes of dissimilatory metabolism. Recently Hodgson \& Chater (1981) mapped a gene controlling extracellular agarase production $(\operatorname{dag} A 1)$ at the 9:00 region of the map of $S$. coelicolor A3(2). The failure of earlier investigators to identify markers in the empty regions might, therefore, be a simple consequence of the almost universal reliance upon glucose or glycerol as carbon and energy source in media on which mutants were detected or selected. Thus, the clustering of independently regulated genes encoding unrelated catabolic enzymes (Wheelis \& Stanier, 1970; Leidigh \& Wheelis, 1973a; deTorrontegui et al., 1976) may be a widespread, possibly fairly general, aspect of genetic architecture in prokaryotes.

This work was supported in part by USPHS-GM predoctoral training grant no. 01041 to Kathleen E. Kendrick.

\section{REFERENCES}

Coote, J. G. \& Hassall, H. (1973a). The degradation of L-histidine, imidazolyl-L-lactate and imidazolyl-propionate by Pseudomonas testosteroni. Biochemical Journal 132, 404-422.

CoOTE, J. G. \& Hassall, H. (1973b). The control of the enzymes degrading histidine and related imidazolyl derivatives in Pseudomonas testosteroni. Biochemical Journal 132, 423-433.

deTorrontegui, G., Diaz, R., Wheelis, M. L. \& Canovas, J. L. (1976). Supra-operonic clustering of genes specifying glucose dissimilation in Pseudomonas putida. Molecular and General Genetics 144, 307-311.

DowDING, J. E. (1973). Characterization of a bacteriophage virulent for Streptomyces coelicolor A3(2). Journal of General Microbiology 76, 163-176.
Dowding, J. E. \& Hopwood, D. A. (1973). Temperate bacteriophages for Streptomyces coelicolor A3(2) isolated from soil. Journal of General Microbiology 78, 349-359.

ECKER, R. E. \& LOCKHART, W. R. (1961). Specific effect of limiting nutrient on physiological events during culture growth. Journal of Bacteriology 82, 511-516.

Ehresmann, B., Imbault, P. \& Weil, J. H. (1973). Spectrophotometric determination of protein concentration in cell extracts containing tRNA's and rRNA's. Analytical Biochemistry 54, 454-463.

Gordon, S. A., Fleck, A. \& Bell, J. (1978). Optimal conditions for the estimation of ammonium by the Berthelot reaction. Annals of Clinical Biochemistry 15. $270-275$. 
Hassall, H. (1971). The separation of histidine degradation products and related imidazoles by paper chromatography and paper electrophoresis. Methods in Enzymology 17, 99-102.

HiRSCH, C. F. \& ENSIGN, J. C. (1975). Germination of Streptomyces viridochromogenes spores. In Spores $V I$, pp. 28-35. Edited by P. Gerhardt, R. N. Costilow \& H. L. Sadoff. Washington, D.C.: American Society for Microbiology.

Hodgson, D. A. \& Chater, K. F. (1981). A chromosomal locus controlling extracellular agarase production by Streptomyces coelicolor A3(2), and its inactivation by chromosomal integration of plasmid SCP1. Journal of General Microbiology 124, 339-348.

HopwOoD, D. A. $(1967 a)$. Genetic analysis and genome structure in Streptomyces coelicolor. Bacteriological Reviews 31, 373-403.

HoPwOOD, D. A. $(1967 b)$. In discussion to F. W. Stahl's paper: circular genetic maps. Journal of Cellular Physiology 70, Suppl. I, 1-12.

Hopwood, D. A., Chater, R. F., Dowding, J. E. \& VIviAN, A. (1973). Advances in Streptomyces coelicolor genetics. Bacteriological Reviews 37, $371-405$.

Kaminskas, E., Kimhi, Y. \& Magasanik, B. (1970). Urocanase and $N$-formimino-L-glutamate formiminohydrolase of Bacillus subtilis, two enzymes of the histidine degradation pathway. Journal of Biological Chemistry 245, 3536-3544.

Leidigh, B. J. \& Wheelis, M. L. (1973a). The clustering on the Pseudomonas putida chromosome of genes specifying dissimilatory functions. Journal of Molecular Evolution 2, 235-242.

LeIDigh, B. J. \& Wheelis, M. L. (1973b). Genetic control of the histidine dissimilatory pathway in Pseudomonas putida. Molecular and General Genetics 120, 201-210.

LENNOX, E. S. (1955). Transduction of linked genetic characters of the host by bacteriophage P1. Virology 1, 190-206.

Lessie, T. G. \& NeIdHARdT, F. C. (1967). Formation and operation of the histidine-degrading pathway in Pseudomonas aeruginosa. Journal of Bacteriology 93. $1800-1810$.

Lund, P. \& Magasanik, B. (1965). N-formiminoL-glutamate formiminohydrolase of Aerobacter aerogenes. Journal of Biological Chemistry 240, 4316-4319.

Meiss, H. K., Brill, W. J. \& Magasanik, B. (1969). Genetic control of histidine degradation in Salmonella typhimurium, strain LT-2. Journal of Biological Chemistry 244, 5382-5391.
Nakayama, T., Munoz, L. \& Doi, R. H. (1977). A procedure to remove protease activities from Bacillus subtilis sporulating cells and their crude extracts. Analytical Biochemistry 78, 165-170.

NeIDHARDT, F. C. \& MAgasanik, B. (1957). Reversal of the glucose inhibition of histidase biosynthesis in Aerobacter aerogenes. Journal of Bacteriology 73, 253-259.

Newell, C. P. \& Lessie, T. G. (1970). Induction of histidine-degrading enzymes in Pseudomonas aeruginosa. Journal of Bacteriology 104, 596-598.

Palleroni, N. J. \& Doudoroff, M. (1972). Some properties and taxonomic subdivisions of the genus Pseudomonas. Annual Review of Phytopathology 10, 73-100.

RAO, D. R. \& Greenberg, D. M. (1961). Studies on the enzymic decomposition of urocanic acid. IV. Purification and properties of 4(5)-imidazolone-5(4)propionic acid hydrolase. Journal of Biological Chemistry 236, 1758-1763.

ReCHLER, M. M. (1969). The purification and characterization of L-histidine ammonia-lyase (Pseudomonas). Journal of Biological Chemistry 244, 551-559.

SABATER, B. \& Asensio, C. (1973). Transport of hexoses in Streptomyces violaceoruber. European Journal of Biochemistry 39, 201-205.

Schlesinger, S., ScotTo, P. \& MAgasanik, B. (1965). Exogenous and endogenous induction of the histidine-degrading enzymes in Aerobacter aerogenes. Journal of Biological Chemistry 240, 43314337.

SegEL, I. H. (1968). Biochemical Calculations. New York: John Wiley.

Silverman, M. (1962). $N^{5}$-formyltetrahydrofolic acid glutamic acid transformylase from hog liver. Methods in Enzymology 5, 790-794.

TABOR, H. \& MEHLER, A. H. (1954). Isolation of $N$-formyl-L-glutamic acid as an intermediate in the enzymatic degradation of L-histidine. Journal of Biological Chemistry 210, 559-568.

Townsend, M. E., Wright, H. M. \& Hopwood, D. A. (1971). Efficient mutagenesis by near ultraviolet light in the presence of 8-methoxypsoralen in Streptomyces. Journal of Applied Bacteriology 34, 799-801.

Vivian, A. \& HoPwOOD, D. A. (1970). Genetic control of fertility in Streptomyces coelicolor A3(2): the IF fertility type. Journal of General Microbiology 64, 101-117.

Wheelis, M. L. \& Stanier, R. Y. (1970). The genetic control of dissimilatory pathways in Pseudomonas putida. Genetics 66, 245-266. 